\title{
Relationship between blood lead concentration and nutritional status among Malay primary school children in Kuala Lumpur, Malaysia.
}

\begin{abstract}
A cross-sectional study was conducted to identify the relationship between blood lead concentration and nutritional status among primary school children in Kuala Lumpur. A total of 225 Malay students, 113 male and 112 female, aged 6.3 to 9.8 were selected through a stratified random sampling method. The random blood samples were collected and blood lead concentration was measured by a Graphite Furnace Atomic Absorption Spectrophotometer. The nutrient intake was determined by the 24-hour Dietary Recall method and Food Frequency Questionnaire. An anthropometric assessment was reported according to growth indices (z-scores of weight-for-age, height-for-age, and weight-for-height). The mean blood lead concentration was low $(3.4 \pm 1.91 \mathrm{ug} / \mathrm{dL})$ and was significantly different between gender. Only $14.7 \%$ of the respondents fulfilled the daily energy requirement. The protein and iron intakes were adequate for a majority of the children. However, $34.7 \%$ of the total children showed inadequate intake of calcium. The energy, protein, fat and carbohydrate intakes were significantly different by gender, that is, males had better intake than females. Majority of respondents had normal mean z-score of growth indices. Ten percent of the respondents were underweight, $2.8 \%$ wasted and $5.4 \%$ stunted. Multiple linear regression showed inverse significant relationships between blood lead concentration with children's age $(\beta=-0.647$, $\mathrm{p}<0.001)$ and per capita income $(\beta=-0.001, \mathrm{p}=0.018)$. There were inverse significant relationships between blood lead concentration with children's age $(\beta=-0.877, \mathrm{p}=0.001)$ and calcium intake $(\beta=-0.011, \mathrm{p}=0.014)$ and positive significant relationship with weight-forheight $(\beta=0.326, p=0.041)$ among those with inadequate calcium intake. Among children with inadequate energy intake, children's age $(\beta=-0.621, p<0.001)$, per capita income $(\beta=-$ $0.001, \mathrm{p}=0.025)$ and protein intake $(\beta=-0.019, \mathrm{p}=0.027)$ were inversely and significantly related with blood lead concentration. In conclusion, nutritional status might affect the children's absorption of lead and further investigation is required for confirmation.
\end{abstract}

Keyword: Blood lead concentration; Nutritional status; School children; Urban. 